\title{
Flow regime transition and liquid distribution in a 3D cocurrent downflow three-phase moving bed
}

\author{
Shaoshuo Li $^{1}$, Yaohui Wang ${ }^{1}$, Yao Yang ${ }^{2}$, Zhengliang Huang ${ }^{1}$, Jingyuan Sun ${ }^{1}$, Zuwei Liao ${ }^{1}$, \\ Jingdai Wang ${ }^{1}$, Yang Yongrong ${ }^{3}$, and Bing DU² \\ ${ }^{1}$ Zhejiang University \\ ${ }^{2}$ Affiliation not available \\ ${ }^{3}$ zhejiang university
}

September 11, 2020

\begin{abstract}
Based on a cold-flow experimental device, the transition between trickle flow and pulse flow in a 3D cocurrent downflow threephase moving bed is investigated by the standard deviation of pressure drop and visual observations. Results show that at a constant gas flow rate, the trickle-to-pulse transition shifts to a higher liquid flow rate with the increasing solid flow rate because the particle moving inhibits the formation of local liquid blockage. Furthermore, an empirical model is proposed to fit the trickle-to-pulse transition boundary by correlating the dynamic liquid holdup at the boundary with the gas Reynolds number and the particle velocity. Finally, the effects of the particle moving on the liquid distribution is investigated, which show that the particle moving makes the liquid distribution more uniform when the solid flow rate is smaller than a certain value. But further increasing the solid flow rate, the liquid distribution becomes uneven
\end{abstract}

Flow regime transition and liquid distribution in a 3D cocurrent downflow three-phase moving bed

Shaoshuo Li $^{1}$, Yaohui Wang ${ }^{1}$, Yao Yang ${ }^{*}$, Zhengliang Huang ${ }^{1}$, Jingyuan Sun ${ }^{1}$, Zuwei Liao ${ }^{1}$, Jingdai Wang ${ }^{1}$, Yongrong Yang ${ }^{1}$, Bing $\mathrm{Du}^{2}$

${ }^{1}$ College of Chemical and Biological Engineering, Zhejiang University,

Hangzhou 310027, P.R. China

${ }^{2}$ ExxonMobil Research and Engineering, 1545 Route 22 East,

Annandale, NJ 08801, USA

Based on a cold-flow experimental device, the transiti on between trickle flow and pulse flow in a $3 D$ cocurrent downflow three-phase moving bed is investigated by the standard deviation of pressure drop and visual observations. Results show that at a constant gas flow rate, the trickle-to-pulse transition shifts to a higher liquid flow rate with the increasing solid flow rate because the particle movinginhibits the formation of local liquid blockage. Furthermore, an empirical model is proposed to fit the trickle-to-pulse transition boundary by correlating the dynamic liquid holdup at the boundary with the gas Reynolds number and the particle velocity. Finally, the effects of the particle moving on the liquid distribution is investigated, which show that the particle moving makes the liquid distribution more uniform when the solid flow rate is smaller than a certain value. But further increasing the solid flow rate, the liquid distribution becomes uneven.

Keywords: three-phase moving bed, flow regime transition, liquid distribution, dynamic liquid holdup, empirical model 


\section{Introduction}

Various multiphase reactors have been developed to meet the specific requirements of diverse multi-phase reactions existing in the chemical industry. The trickle bed reactor, for instance, is mainly developed for slower reactions requiring high catalyst loading (volume fraction more than $30 \%$ ), particularly for the largescale processes ${ }^{1}$. In addition, due to the flexibility and simplicity in operation, it has been widely used in chemical and petroleum processes ${ }^{2}$. In trickle bed reactors, the gas and liquid can flow cocurrently downward through the packed bed and conventionally the gas works as the continuous phase while the liquid trickles over particles in the form of films or rivulets ${ }^{3,4,5}$. The trickle bed reactors offer several advantages like plug flow operation, a high catalyst to liquid ratio, lower power requirements and so on ${ }^{6}$. However, it also has some intrinsic drawbacks like uneven liquid distribution, poor heat transfer rates, significant diffusion resistance $^{7}$. Therefore, it is vital to balance different competing requirements for a particular application. For example, using larger catalyst particles can reduce the pressure drop, however, the intraparticle diffusion resistance will be enhanced ${ }^{8}$. In recent years, considering the specific requirements of different applications, new modifications of conventional trickle bed reactors like monolith reactors and micro-trickle bed reactors have been developed, which may minimize some of the inherent drawbacks of the traditional trickle bed and enlarge the application of trickle bed reactors significantly ${ }^{9,10,11}$. However, there is no modification for the strong exothermic reactions with rapid deactivation rate of catalysts ${ }^{12}$. The configuration of the moving bed has been proven to be a promising alternative by Iliuta in catalytic wet oxidation ${ }^{13}$ and ChevronTexaco ${ }^{14}$ in hydrodemetallization of heavy oil, which can realize an online replacement of catalysts. Therefore, a novel moving bed reactor concept based on cocurrent downflow of gas, liquid, and solid phases has been proposed by our research team and scientist in ExxonMobil to supply a potential solution for the reactions with rapid deactivation rate of catalysts as well as high catalyst loading. This new reactor concept not only has the same characteristics as a conventional moving bed reactor with continuous catalyst regeneration capability but also has some of the advantages of the trickle bed. Moreover, it is further assumed that the complex particle movements may potentially enhance the local turbulent intensity and increase the heat and mass transfer rates.

In our previous work, we have investigated the pressure drop in a 3D three-phase moving bed ${ }^{15}$ and the flow regimes in a rectangular three-phase moving bed ${ }^{16}$. Results show that the pressure drop decreases almost linearly with the increasing solid flow rate within our operating limits and it can be correlated well by coupling the solid flow rate with the Clements' correlation developed for the trickle bed. Besides, the typical flow regimes in trickle bed including the trickle flow, the pulse flow and the bubble flow are all observed in the rectangular three-phase moving bed, but the transition boundary between different flow regimes is significantly influenced by particle movement. More importantly, it shows from the aspect of flow regimes that the three-phase moving bed may be suitable for reactions that occur in pulse flow, which may increase the liquid loading significantly. However, although the flow regimes investigation in rectangular three-phase moving bed has supplied important information, it is not enough for the design and application of three-phase moving bed in the real process, since results in rectangular apparatus may be influenced by wall effects more or less. Therefore, this work will investigate the flow regimes in a 3D cylinder-shaped three-phase moving bed for the first time. Since results in the rectangular apparatus have shown that the flow regimes in three-phase moving bed have some similarity with those in trickle bed, we will also use the flow regime map in the 3D trickle bed as a basis. Besides, considering the large driving forces of particles on the liquid phase and the liquid distribution is significant for the development of flow regimes, this work will also investigate the liquid distribution in three-phase moving bed.

In a trickle bed, based on the nature of individual phase flow, four flow regimes can be distinguished, specifically the trickle, pulse, bubble and spray flow regime ${ }^{17,18,19}$. At low gas and liquid flow rates, the liquid trickles over the packed particles in the form of films or rivulets and the gas flows through the 
remaining interstices. Such a flow pattern is generally called as the trickle flow or low interaction regime in which both gas and liquid phases are continuous ${ }^{20}$. Weak gas-liquid interaction, low shear stresses at gas-liquid interfaces and gravity-driven liquid flow are characteristics of the low interaction regime ${ }^{21}$. The trickle flow regime region widens with the increase in particle size, decreases in liquid viscosity and surface tension $^{22}$. Due to the low gas-liquid interaction, the pressure drop is low and fluctuates slightly ${ }^{23}$. As the gas and liquid flow rates increase, the gas-liquid interaction increases, the solid surface changes from partial wetting to complete wetting, and liquid pockets or plugs constantly block the entire cross-section, leading to the alternation of gas-rich and liquid-rich regions. The corresponding regime is classified as the pulse flow regime or high interaction regime in which both gas and liquid phases are semi-continuous ${ }^{24}$. The alternation of gas-rich and liquid-rich slugs results in significant pressure fluctuations. The pulse flow regime offers characteristic advantages in terms of effective wetting and utilization of catalyst, and higher heat and mass transfer rates ${ }^{25}$. At low gas flow rate and high liquid flow rate, the liquid phase becomes a continuous phase filling the entire bed, while the gas phase flows downward through the bed in the form of dispersed bubbles. This is known as the bubbling flow, in which the surface of the particles is completely wetted. Due to the high liquid holdup and complete wetting of the bed, bubbling flow is suitable for liquid phase restricted reaction and strong exothermic reaction ${ }^{2}$. At the high gas flow rate and low liquid flow rate, subjected to the high shear caused by the gas-liquid slip velocity, liquid phase loses its semi-continuity and turns into droplets, and gas phase becomes the continuous phase ${ }^{26}$. This regime is called as the spray flow regime.

Most of the trickle bed reactors are operated close to the boundary between trickle flow and pulse flow regime, taking both advantages of these two operating regimes. As a result, most of the experimental studies on the trickle bed were restricted to trickle and pulse flow regimes. Numerous methods have been developed to identify the flow regime transition from trickle flow to pulse flow, which includes the visual observations $^{27}$, pressure drop fluctuation ${ }^{28}$, microelectrodes ${ }^{29}$, computed tomography $(\mathrm{CT})^{30}$ and magnetic resonance imaging $(\mathrm{MRI})^{31,32,33}$. The same to that in the trickle bed, this work also mainly focused on the transition between trickle flow and pulse flow in the 3D three-phase moving bed.

In summary, this work is organized as follows. Firstly, the new developed three-phase moving bed is worked as a trickle bed setting the solid flow rate as 0 , and the flow regime map in it is established as a basis. Then, the transition between trickle flow and pulse flow is analyzed when particles start to move in the three-phase moving bed, based on the variation of pressure drop signals and the observations from the wall. According to the experimental results at different solid flow rates, the hydrodynamic parameters governing the transition between the trickle flow and the pulse flow are given. Meanwhile, a correlation for the transition boundary is established by relating the parameters governing the flow regime transition between trickle flow and pulse flow. Finally, the effect of particle movements on the radial liquid distribution is further analyzed.

\section{Experimental apparatus and methods}

The schematic of the experimental apparatus is shown in Figure 1a, which mainly consists of two parts, a three-phase moving bed and a silo. The three-phase moving bed is made of Plexiglass with an inner diameter of $129 \mathrm{~mm}$ and a bed height of $1100 \mathrm{~mm}$. A gas distributor and four liquid nozzles are installed at the top of the bed to ensure uniform distribution of gas and liquid. The bed has a conical bottom formed by the 2-mm mesh screen, and a discharge pipe with an inner diameter of $30 \mathrm{~mm}$ is installed in the center of the bottom. During the experiments, gas and liquid can flow out of the bed through both the mesh screen and the discharge pipe, while the particles can only flow out through the central discharge pipe. A collector is equipped at the bottom of the bed to facilitate the measurement of liquid distribution over the cross-section of the bed, as shown in Figure 1b. It can be seen from the figure that the collector consists of three annular rings dividing the cross-section of the bed into four annular sections, and the dimensions of the annular areas and annular fractions are given in Table 1. The rings extend into the bed with different lengths to prevent the liquid from migrate radially on the screen and form a 45-degree tapered slope to facilitate the catalyst withdrawal. The upper edge of the rings is beveled to a fine line to reduce the disturbance to 
the flow distribution caused by the collector rings. Each annular section is filled with catalyst particles to prevent overflow of liquid from one annular section to an adjacent section. Preliminary measurements show no overflow within the range of gas and liquid mass flow rates studied. Each annular section contains four discharge tubes located symmetrically in the bottom plate. The discharge tube is connected to a vessel which is open to the atmosphere to vent the air. The liquid mass flow rate through each section is measured by sampling and weighing within $15 \mathrm{~s}$. A silo with an inner diameter of $1400 \mathrm{~mm}$ and a height of $1200 \mathrm{~mm}$ is installed directly above the three-phase moving bed to ensure a continuous and steady flow of particles during the experiment. In order to balance the pressure of the system and ensure the stable flow of the particles, the bed and the silo are connected by a balance tube.

Table 1. Dimensions of the collector

\begin{tabular}{lllll}
\hline Number of the annular sections & 1 & 2 & 3 & 4 \\
\hline Inner diameter, mm & 30 & 60 & 98 & 129 \\
Area, mm $^{2}$ & 706.86 & 2023.18 & 4523.89 & 5215.83 \\
\% of total area & 5.67 & 16.22 & 36.28 & 41.83 \\
\hline
\end{tabular}

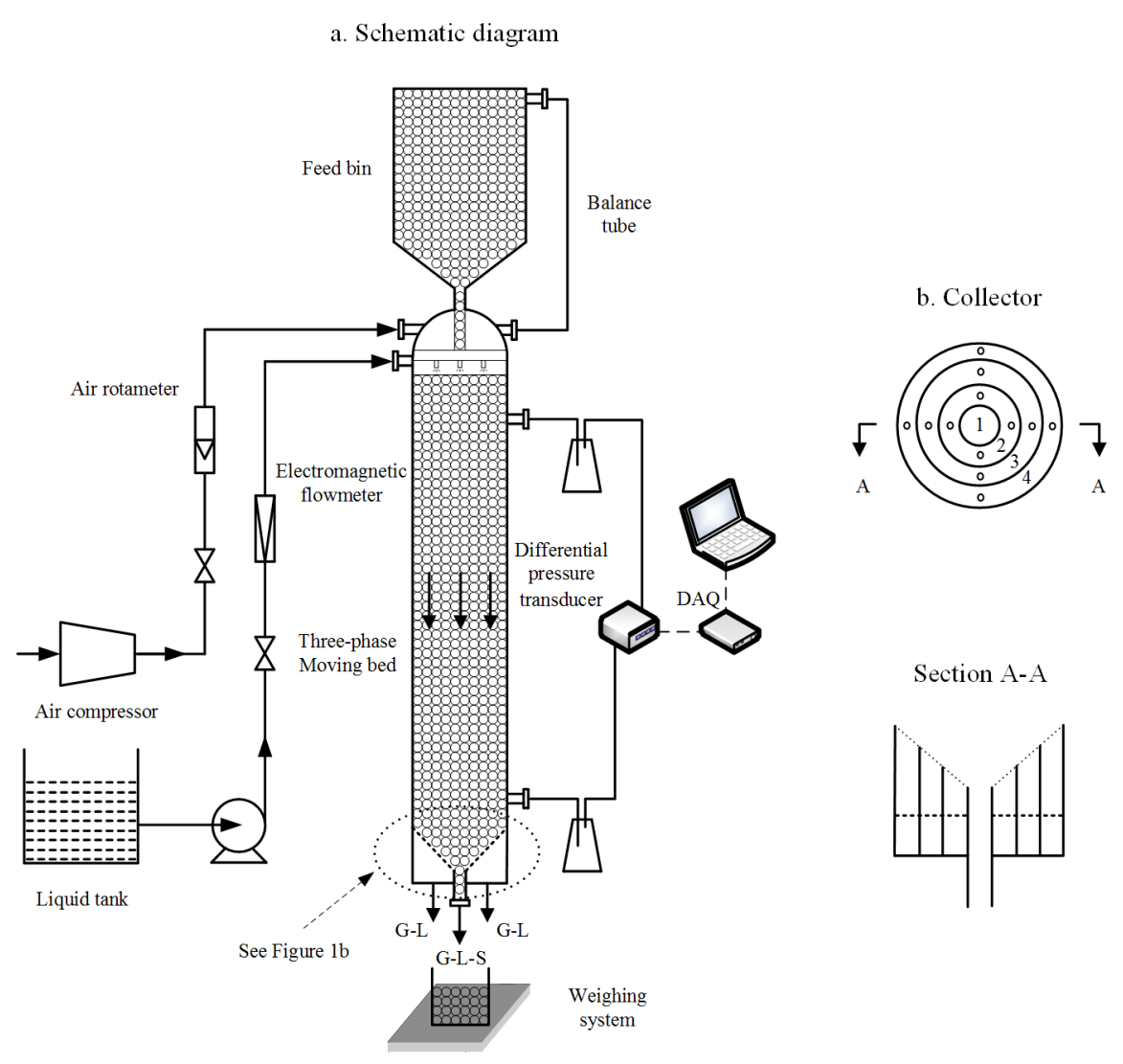

Figure 1. Schematic diagram of experimental setups

The ancillary equipment for the whole experimental system includes the gas and liquid flowmeters, air compressor, liquid pump, and water tank. All experiments done in this study are in the cold flow manner, and the gas, liquid and solid phase are air, water and spherical particles, respectively. Provided by the air compressor, the gas is metered by the rotameters and enters radially into the bed through the gas distributor. 
The water, pumped by the multistage pump, is metered by the electromagnetic flowmeter then evenly sprays into the column on the top of the particles through the nozzles. Spherical particles with an average diameter of $2.4 \mathrm{~mm}$, saturated water absorption of $21 \%$ and a bulk density of $1.04 \mathrm{~g} / \mathrm{cm}^{3}$, are continuously added into the top of the bed from the silo. This reactor operates in a downflow state: the gas, liquid, and solid phases flow cocurrently downward through the bed after pre-distribution and exit from the bottom of the bed. The outlet pipe is open to the atmosphere to vent out the air. The solid flow rate is controlled by a gate valve on the central outlet pipe and measured by weighting. To identify the solid flow rate, first, collect and weigh all the liquid and solid flowing out within a certain time, and then subtract the liquid to obtain the mass of saturated water-absorbing particles. It is worth saying that the mass of liquid flowing out of the bed is easy to be acquired by the liquid flowmeter since the mass of liquid flowing out of the bed in unit time is equal to the liquid injection rate in a steady state. The experiments are carried out at room temperature $(25 \pm 1)$ and near atmospheric pressure. The range of the operating conditions in this study is shown in Table 2.

Table 2. Range of independent variables in present study

\begin{tabular}{ll}
\hline Variables & Range \\
\hline Gas mass flow rate $(G), \mathrm{kg} \cdot \mathrm{m}^{-2} \cdot \mathrm{s}^{-1}$ & $0.050-0.214$ \\
Liquid mass flow rate $(L), \mathrm{kg} \cdot \mathrm{m}^{-2} \cdot \mathrm{s}^{-1}$ & $3-35$ \\
Solid flow rate ()$, \mathrm{mm} \cdot \mathrm{s}^{-1}$ & $0-6$ \\
\hline
\end{tabular}

In order to ensure that the initial conditions of the experiment are consistent and reach a steady-state as soon as possible, pre-wetting of the particles was carried out as follows according to the Levec pre-wetting method $^{34}$. The particles were completely immersed in water for $20 \mathrm{~min}$, then placed in a stainless drum with a screen at the bottom and naturally filtered for $30 \mathrm{~min}$. The pre-wetted particles were fed into the silo to ensure a continuous and stable flow of particles during the experiment. Since the first bed layer packed by free-falling of particles had lower bed porosity, it would take at least one bed volume time to ensure the densely packed bed had been entirely discharged ${ }^{14}$. And during the experiment, each time the experimental conditions were changed, it was necessary to wait for at least 10 min to ensure that the system had reached a steady state.

The pressure drop and exit liquid distribution were acquired simultaneously in the same bed. The pressure drop was measured by the differential pressure transducer (CYG1219 type, Baoji Research Center of Transducer, China). The measuring range is $0-30 \mathrm{kPa}$, with a relative accuracy of $\pm 0.25 \%$ on the full scale. The sampling frequency was set as $400 \mathrm{~Hz}$ and the sampling time was set as $180 \mathrm{~s}$ in all cases. At the top and bottom of the column, two pressure pipes were inserted via drills (distance $750 \mathrm{~mm}$ ). The front end of the pressure pipe was covered with a screen to prevent particles from entering the pressure measuring system. The gas-liquid separators were installed between the pressure pipes and the differential pressure transducer to maintain the pressure measurement completely in a single-phase gas condition according to $\mathrm{Sai}^{35}$. The dynamic liquid holdup was measured by switching off the inlet gas and liquid flows and collecting the drained liquid within $30 \mathrm{~min}$.

In order to quantify liquid distribution at the outlet, a maldistribution factor $M_{f}$ was defined according to the following equation ${ }^{36}$ :

In Eq. (1), $N$ accounts for the number of collectors (4 in this case), $L_{i}$ is the liquid mass flow rate through a given collector referenced by $i$ and $L_{\text {mean }}$ is the mean mass flow rate through all sections of the bed. 


\section{Results and discussion}

\section{Typical regime transition in the trickle bed}

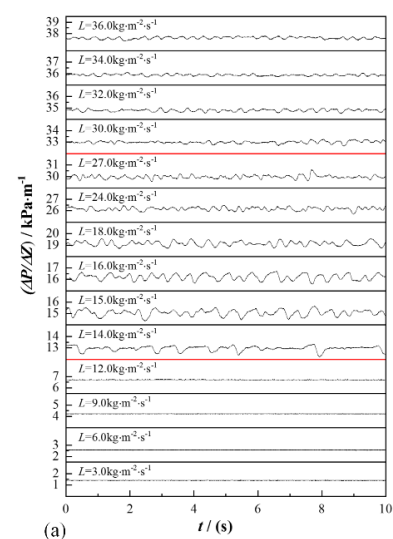

(a)
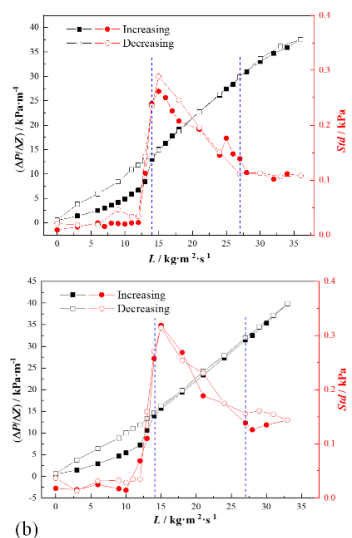

(b)

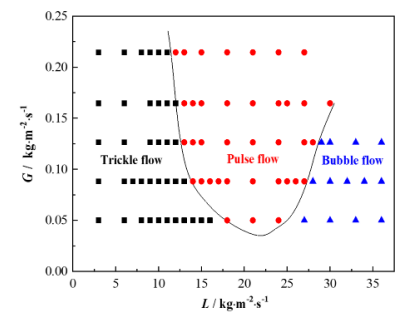

(c)

Figure 2. (a) Typical time-series pressure fluctuations in the trickle bed $\left(G=0.088 \mathrm{~kg} \cdot \mathrm{m}^{-2} \cdot \mathrm{s}^{-1}\right)$,

(b) Typical pressure drop hysteresis and variations of standard deviation of pressure drop in the trickle bed (up: $G=0.088 \mathrm{~kg} \cdot \mathrm{m}^{-2} \cdot \mathrm{s}^{-1}$, down: $G=0.126 \mathrm{~kg} \cdot \mathrm{m}^{-2} \cdot \mathrm{s}^{-1}$ ),

\section{(c) Typical flow regime map in the trickle bed}

In order to verify the accuracy of experimental design in this work and provide a basis for subsequent analysis, the flow regimes in the trickle bed were investigated firstly. The variation of the standard deviation of pressure drop and the pressure drop hysteresis were first checked up for identification of flow regime transition in the trickle bed reactors. Figure 2(a) shows typical time series pressure drop fluctuations for various liquid mass flow rates at a given gas mass flow rate $\left(G=0.088 \mathrm{~kg} \cdot \mathrm{m}^{-2} \cdot \mathrm{s}^{-1}\right)$, which are different as the liquid mass flow rate increases and the flow regime transforms from low to high interaction regime. When the flow regime transforms from trickle flow to pulse flow and even reaches the bubble flow regime, the pressure fluctuation increases firstly and then decreases. This is because the gas-liquid interaction increases when the alternation of gas-rich and liquid-rich regions appears, but decreases when the liquid changes to continuous phase with the increasing liquid flow rate. The standard deviation determined from the pressure drop signals is used as a criterion to distinguish flow regimes, and it is compared with the transition determined by the visual observations. The typical images and videos used to identify the flow regime transition are given in supporting information. At a constant gas mass flow rate, the variations of pressure drop and the standard deviation of pressure drop fluctuations during the increasing and decreasing branches were measured and shown in Figure 2(b). It can be seen from the Figure 2(b) that at the constant gas mass flow rate, the standard deviation of pressure drop increases firstly and then decreases before levelling off as the liquid mass flow rate increases. Indicating that at a constant gas mass flow rate, the flow regime transforms from trickle flow to pulse flow and further transforms to bubble flow as the liquid mass flow rate increases, which is also proved in the work of Chou et al. ${ }^{37}$. As for the pressure drop hysteresis, it can be seen from Figure 2(b) that the difference of the pressure drop between the increasing and decreasing branches exists in the trickle flow regime, which is due to the different bed wetting characteristics while increasing and decreasing the liquid mass flow rate. While the difference of the pressure drop between the increasing and decreasing branches disappears when the flow regime transforms to pulse flow. This is in accordance with the experiment conducted by Gunjal et al. ${ }^{5}$. In the increasing branch, the liquid flow pattern transforms from rivulet to film in the trickle flow regime as the liquid mass flow rate slowly increases from zero. The bed becomes completely wet and the liquid flow changes into the film just before the transition to a pulse flow regime occurs. While 
the liquid is always in the form of film in the decreasing branch as the liquid flow rate decreases slowly back to zero ${ }^{38}$. This effect is negligible in pulse flow regime since the liquid flow pattern does not change during the increasing and decreasing branches.

Based on the standard deviation of pressure drop mentioned above and the visualization, a flow regime map in the trickle bed as a function of gas and liquid mass flow rates was constructed and shown in Figure 2(c), which is similar to the typical flow regime maps mentioned in the literature by $\mathrm{Sie}^{39}$ and Gunjal ${ }^{5}$. It can be seen that there are three flow regimes including the trickle, pulse and bubble flow. At the constant gas mass flow rate, starting from the low liquid mass flow rate, the first regime to be identified is the trickle flow, characterized by independent and continuous flow channels of gas and liquid. A further increase in the liquid mass flow rate leads to a pulse flow pattern characterized by the alternation of gas-rich and liquid-rich regions. Finally, the flow regime transforms to bubble flow with the further increase of liquid mass flow rate, and the liquid flows continuously through the bed while the gas flows as bubbles. This provides a basis for the study of flow regimes in three-phase moving beds.

\section{New transition in the three-phase moving bed}

\section{Trickle-to-pulse transition under effects of particle moving}

The solid state is a vital difference between the novel three-phase moving bed and the conventional trickle bed. Therefore, the solid flow rate was set to several values to investigate the effects of particle moving on the flow regime transition. Due to the following two aspects, this work only focuses on the transition between the trickle flow and the pulse flow. Firstly, as stated in the introduction, the industrial reactors are often operated close to the flow transition boundary between trickle flow and pulse flow to realize better mass transfer rates and catalyst utilization. Secondly, there is no efficient method to identify the bubble flow in the trickle bed reactors except the visualization method. However, when particles start to move, the bubbles could not be observed clearly from the sidewall in a cylindered three-phase moving bed, thus it is hard to identify the transition from pulse flow to bubble flow. Therefore, the experimental studies in this work are restricted to trickle and pulse flow regimes.

In the cocurrent downflow three-phase moving bed, it was observed the presence of trickle flow and pulse flow which almost had the same characteristics as those presented in the typical trickle bed. The transition from the trickle flow to the pulse flow in the three-phase moving bed was mainly determined by the standard deviation of pressure drop and visual observation. The typical images and videos used to identify the flow regime transition are given in supporting information. The variations of pressure drop and the standard deviation of pressure drop with the liquid mass flow rate at a given gas mass flow rate are shown in Figure 3, which also shows a comparison with the observed flow regime transition. It can be seen from Figure 3 that the standard deviation of pressure drop increases suddenly at a certain liquid mass flow rate under all solid flow rates, and the corresponding increasing points vary with the solid flow rate. In addition, the increasing points of standard deviation are close to the observed transition points between trickle flow and pulse flow. This can be explained by the fact that under these conditions, the gas-liquid interaction increases suddenly due to the appearance of pulses, indicating the flow regime transforms from trickle flow to the pulse flow. 

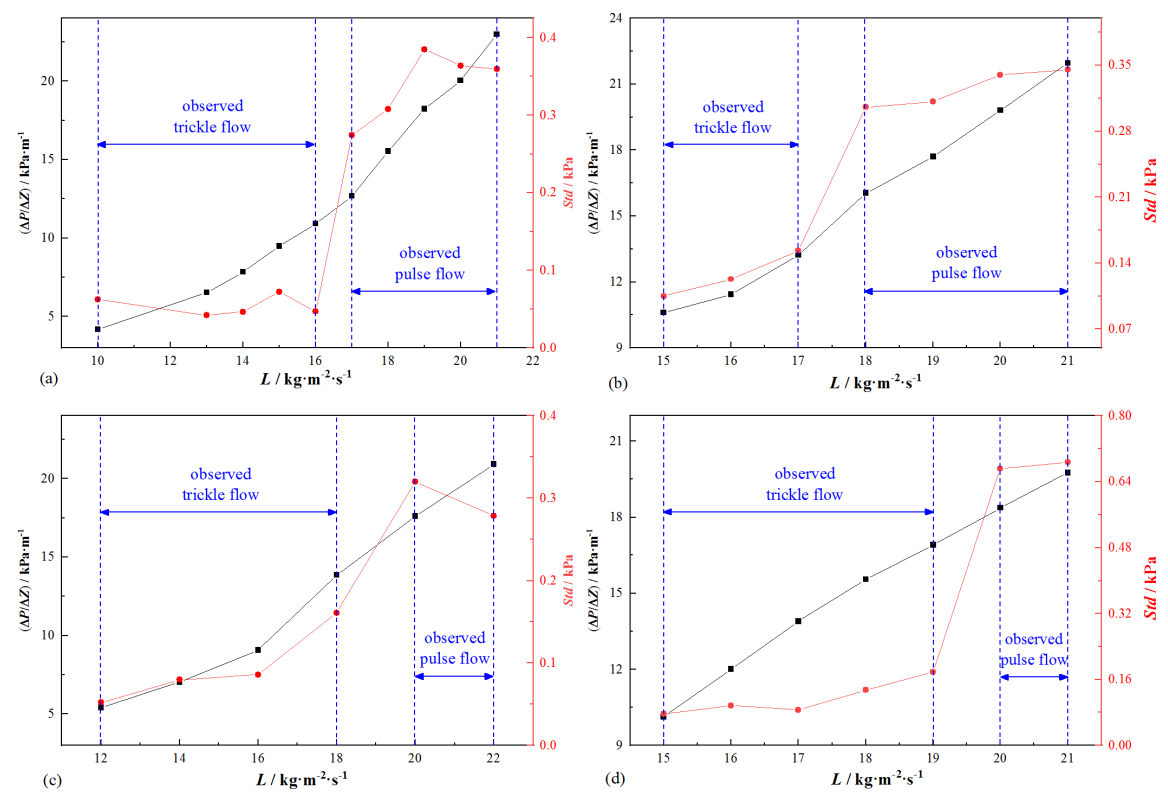

Figure 3. The variations of pressure drop and standard deviation with liquid mass flow rate $(G$ $=0.126 \mathrm{~kg} \cdot \mathrm{m}^{-2} \cdot \mathrm{s}^{-1}$ ) (a) $u_{s}=1 \mathrm{~mm} \cdot \mathrm{s}^{-1}$, (b) $u_{s}=2 \mathrm{~mm} \cdot \mathrm{s}^{-1}$, (c) $u_{s}=3 \mathrm{~mm} \cdot \mathrm{s}^{-1}$, (d) $u_{s}=5 \mathrm{~mm} \cdot \mathrm{s}^{-1}$

In order to establish the transition boundary between trickle flow and pulse flow in the three-phase moving bed, several combinations of gas and liquid mass flow rate in a broad range were adopted at different solid flow rates. Based on the standard deviation and the visual observation methods, the transition boundary between the trickle flow and the pulse flow in the three-phase moving bed was distinguished and shown in Figure 4. As can be seen from Figure 4 that the transition boundary between the trickle flow and pulse flow tends to decrease as the liquid mass flow rate increases at any given solid flow rate. This result is coherent with the observations in the trickle bed reported by several authors ${ }^{18,21,40,41}$. It is worth noting in Figure 4 that the transition depends strongly on the solid flow rate. At the constant gas mass flow rate, the increase of the solid flow rate makes the transition boundary shift rightwards to a higher liquid mass flow rate. 


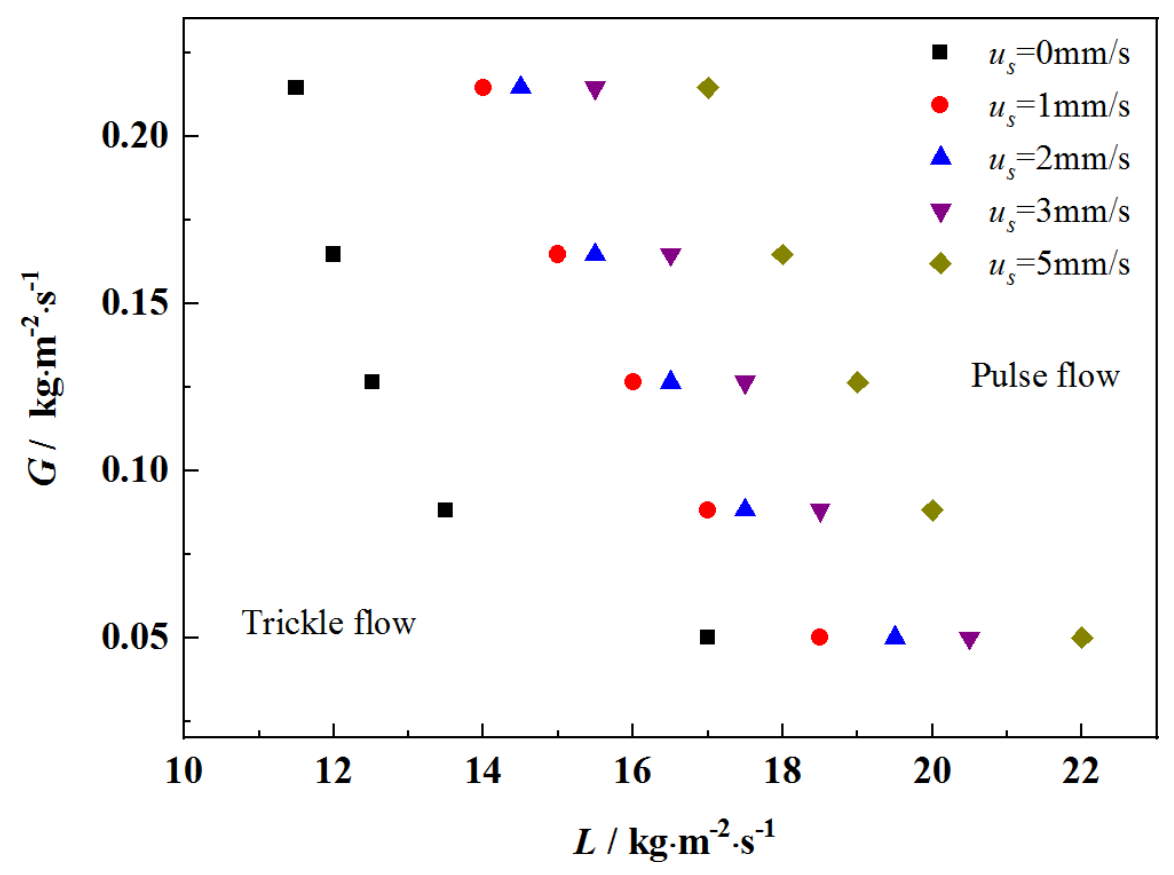

Figure 4. Transition boundary between the trickle flow and the pulse flow at different solid flow rates in the three-phase moving bed

The transition boundary shown in Figure 4 indicates that the pulse flow in the trickle bed will transform to the trickle flow under the effects of the particle moving. In the following part, we will analyze the reason for this transition. As mentioned by Zhao ${ }^{33}$, the pulse flow is caused by the alternation of liquid-rich and gas-rich zones. Two conditions need to be satisfied for the generation of the pulse flow. Firstly, the local liquid blockages should generate between the particles. Secondly, the driving force from the momentum of the gas phase should be greater than the resistance force to push the liquid blockages downward. When the bed operates in the pulse flow regime, the gas mass flow rate is high enough to meet the requirement that the momentum of gas phase is much higher than the resistance for the given mass flow rates of the gas and liquid. The second condition is already satisfied for the given mass flow rates of the gas and liquid. Therefore, it can be deduced that at constant gas and liquid mass flow rates, the transition from the trickle flow to the pulse flow is dominated by the formation of the local liquid blockage. As the particles start to move and the bed is switched from fixed to moving bed, the flow pattern transforms from the pulse flow to the trickle flow, which means that the movement of particles has a significant impact on the formation of the local liquid blockage.

To get a better understanding of the transition phenomenon in the three-phase moving bed, we have also measured the time series pressure drop fluctuation and the dynamic liquid holdup under the operating conditions near the flow regime boundary. At the given gas and liquid mass flow rates $\left(G=0.126 \mathrm{~kg} \cdot \mathrm{m}^{-2} \cdot \mathrm{s}^{-1}\right.$, $L=15 \mathrm{~kg} \cdot \mathrm{m}^{-2} \cdot \mathrm{s}^{-1}$ ), the flow pattern was pulse flow in the trickle bed, but when the particles started to move, it changed to the trickle flow. Under these conditions, the time-series pressure fluctuations at various solid flow rates are shown in Figure 5(a), which shows the flow behaviors from macro-scope. When the solid flow rate was $0 \mathrm{~mm} / \mathrm{s}$, the liquid pockets or plugs constantly blocked the entire cross-section, leading to the alternation of gas-rich and liquid-rich regions. The alternation of gas-rich and liquid-rich slugs resulted in significant pressure fluctuation, as shown in Figure 5(a). As the particles started to move, the bed was switched from fixed to moving bed, the fluctuation of pressure drop changed to be relatively stable compared to that in the trickle bed $\left(u_{s}=0 \mathrm{~mm} / \mathrm{s}\right)$. This indicated that, at the given gas and liquid mass flow rates, the flow pattern transformed from the pulse flow to the trickle flow after particles started to move. The variations of pressure drop and standard deviation of pressure drop under different solid flow rates are shown 
in Figure 5(b). In the operation of moving bed, it can be seen from Figure 5(b) that the pressure drop decreases with the increasing solid flow rate at the given gas and liquid mass flow rates, which is caused by an increase in voidage with the increasing solid flow rate. Such a trend is in agreement with the observations of our previous work ${ }^{15}$. As the voidage increases, the transition from the trickle flow to the pulse flow gets delayed $^{37}$. Meanwhile, it can also be seen from Figure 5(b) that at the constant gas and liquid mass flow rates, as the solid flow rate increases, the standard deviation of pressure drop increases, which may be due to the gas-liquid interaction becomes more and more intense with the increasing solid flow rate. However, even the solid flow rate is up to $6 \mathrm{~mm} / \mathrm{s}$, the standard deviation of pressure drop is still much lower than that in the trickle bed, which proves that the flow regime is always maintained in the trickle flow.
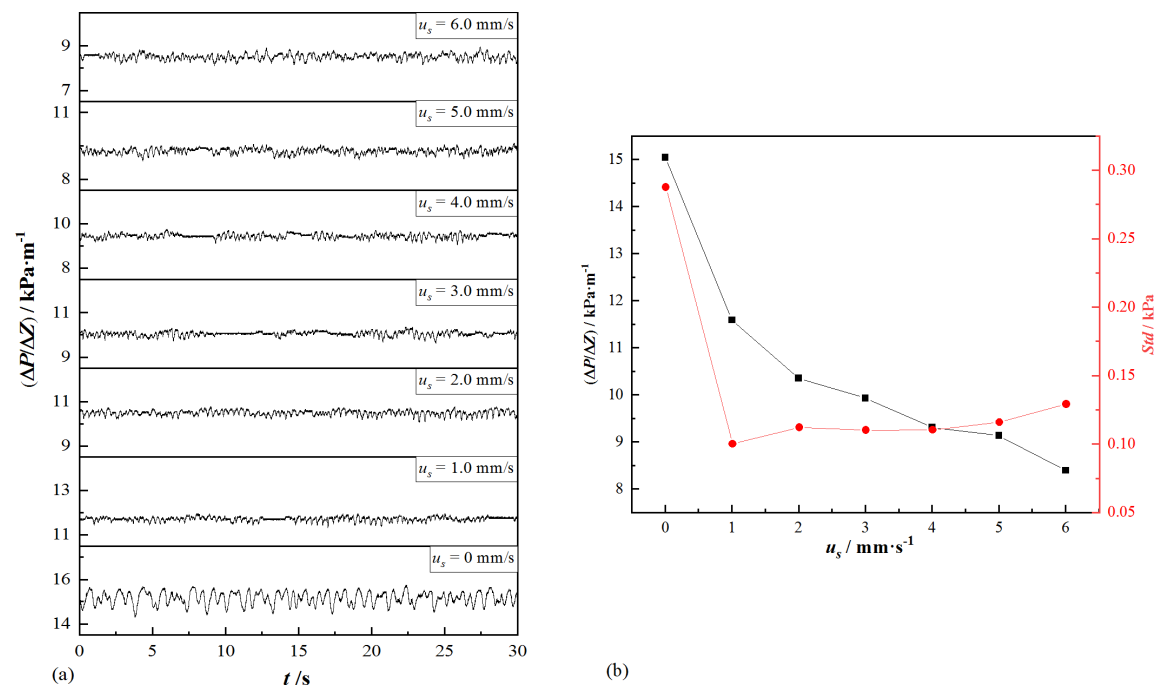

(b)

Figure 5. (a) Time-series pressure drop fluctuations and (b) the variations of pressure drop and standard deviation of pressure drop under different solid flow rates

$$
\left(G=0.126 \mathrm{~kg} \cdot \mathrm{m}^{-2} \cdot \mathrm{s}^{-1}, L=15 \mathrm{~kg} \cdot \mathrm{m}^{-2} \cdot \mathrm{s}^{-1}\right)
$$

Figure 6 shows the effect of the solid flow rate on the dynamic liquid holdup at different liquid mass flow rates in the three-phase moving bed. As evident in these figures, the dynamic liquid holdup increases with the liquid mass flow rate. On the contrary, the dynamic liquid holdup decreases with the gas mass flow rate because of the displacement of the liquid phase by the gas phase. Such trends are in agreement with the observation in the trickle bed by Larchi et al. $^{42}$. It should be noted that the dynamic liquid holdup all decreases with the solid flow rate at any given gas and liquid mass flow rates. In other words, the dynamic liquid holdup is noticeably influenced by the value of the solid flow rate under the operating conditions near the flow regime boundary. Therefore, when the bed is operated in the pulse flow regime and the particles start to move, the dynamic liquid holdup will decrease to a steady value lower than that to initiate the pulse flow. In details, the liquid film on the particles, which is proportional to the dynamic liquid holdup ${ }^{43}$, is too thin to collapse in the interstices between the particles, so no pulses can be formed any more. The influence of the solid flow rate on the dynamic liquid holdup gives us a qualitative explanation for the transition boundary shift in Figure 4. 

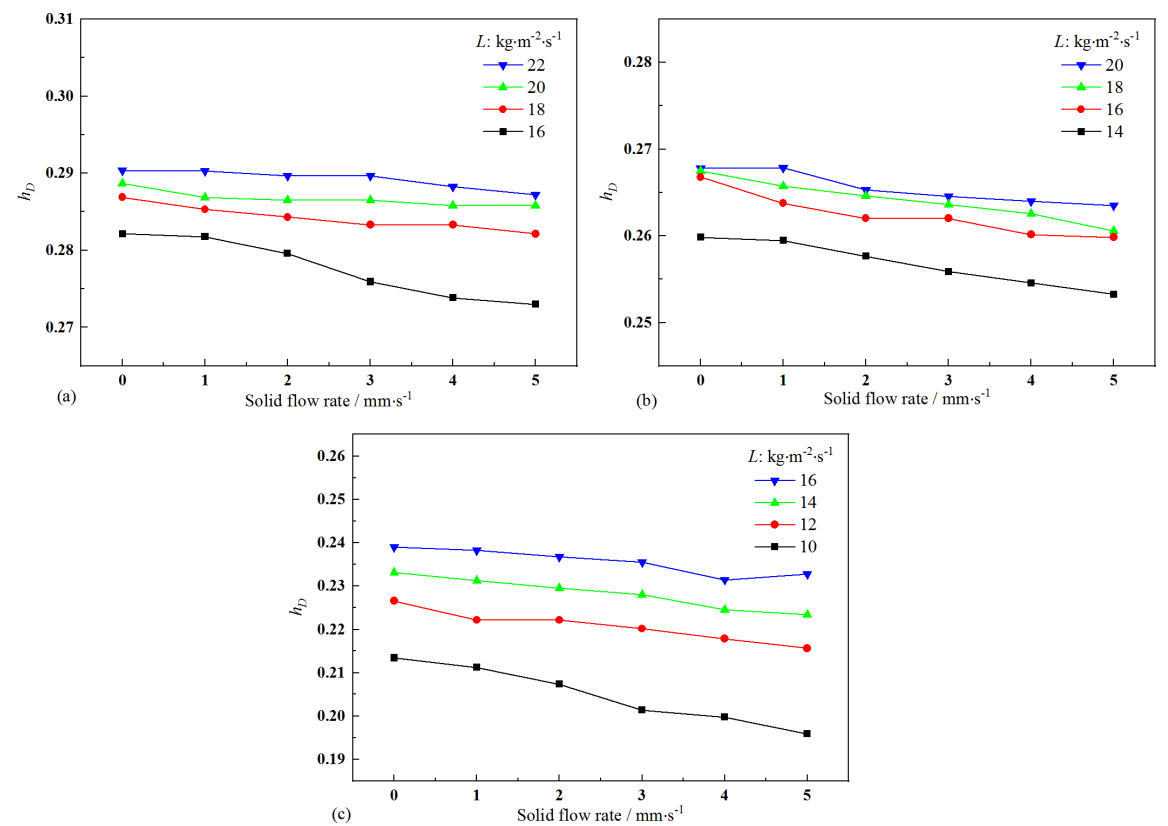

Figure 6. Effect of solid flow rate on dynamic liquid holdup at different liquid mass flow rates in the three-phase moving bed

(a) $G=0.050 \mathrm{~kg} \cdot \mathrm{m}^{-2} \cdot \mathrm{s}^{-1}$, (b) $G=0.126 \mathrm{~kg} \cdot \mathrm{m}^{-2} \cdot \mathrm{s}^{-1}$, (c) $G=0.214 \mathrm{~kg} \cdot \mathrm{m}^{-2} \cdot \mathrm{s}^{-1}$

Besides, according to the visual observations, the movement of particles would break up the liquid pockets or plugs between particles, and inhibited the formation of local liquid blockages. Above all, the movement of particles affected the formation of local liquid blockages in three ways:

(1) The voidage increased with the solid flow rate,

(2) The dynamic liquid holdup decreased with the solid flow rate,

(3) The movement of particles would destroy the liquid pockets or plugs between particles.

As a result, some pulse flow in the trickle bed shifted to trickle flow when particles started to move because the movement of particles inhibited the formation of local liquid blockage. Meanwhile, the liquid mass flow rate required to form the local liquid blockage and initiate the pulse was increased, and the transition boundary from trickle flow to pulse flow in the three-phase moving bed shifted rightwards at a higher solid flow rate as shown in Figure 4.

\section{Prediction of the trickle-to-pulse transition boundary}

Previous studies have shown that the hydrodynamics are different in each flow regime. Therefore, it is important to predict flow regime boundary accurately for the design and scale-up of the three-phase moving bed. It can be seen from Figure 4 that the trickle and pulse flow still exist in the three-phase moving bed, which have the same characteristics as those presented in the trickle bed. Thus, the models developed for the prediction of the transition between the trickle flow and the pulse flow in the trickle bed can work as a basis for the prediction in the three-phase moving bed.

Although researchers have conducted model research on flow regime transition for many years, estimation of the trickle to pulse flow regime transition in the trickle bed is still not very accurate ${ }^{44}$. Earlier models attempted to relate the inception of pulse flow to a pore-scale phenomenon, which assumed that the pulsing inception was due to the liquid pockets blocked the interstices between particles ${ }^{45}$. While recent models 
considered it as a macroscopic scale phenomenon, which assumed that the pulsing inception was related to the instability in the liquid film due to the gas shear ${ }^{46}$. Though macroscopic models were in good agreement with the experimental data, the pore-scale physical phenomenon was also important in the inception of the pulse flow. Up to now, the understanding of the inception of pulse flow is limited, so theoretical prediction of flow regime transition is difficult. In summary, although researchers have tried to establish a mechanism model for the prediction of flow regime transition in trickle bed, the published models are still mainly empirical based on the correlations of experimental data. Considering that in the three-phase moving bed the multi-phase interactions will be more complex due to the movement of particles, the empirical approach is still used in this work to establish a model for the estimation of transition boundary in the three-phase moving bed.

Wammes attempted to develop models based on the physical understanding of the transition ${ }^{40}$. In his opinion, the mean thickness of the liquid film on the particle surface was proportional to the dynamic liquid holdup. When the thickness of the liquid film was enough to collapse in the interstices between particles, the pulses would be formed. A correlation had been derived based on a criterion that assumed the transition occurring at some critical dynamic holdup and it related the operating parameters as follows:

where, $C=0.27$ for water- $\mathrm{N}_{2}$ and 0.32 for $40 \%$ ethylene glycol- $\mathrm{N}_{2}, ?_{t, t r}$ is the total liquid holdup at the transition and $u_{g}$ denotes the superficial gas velocity.

In the trickle bed, the trickle-to-pulse flow transition boundary of the system in this work was obtained and shown in Figure 2(c). Based on equation (2), the prediction model for the trickle bed in this work could be fit as follows:

In the three-phase moving bed, considering that the dynamic liquid holdup decreased with the increase of the solid flow rate, we first tried to just introduce the effect of solid flow rate on the dynamic liquid holdup into equation (3) to develop a model for the prediction of trickle-to-pulse transition. The dynamic liquid holdup in three-phase moving bed was correlated with the gas and liquid Reynolds numbers and the solid flow rate. The coefficients were obtained by multiple regression techniques, and it could be expressed as equation (4). The equation (4) could describe the dynamic liquid holdup at the flow regime transition with an average relative error of $1.99 \%$.

By combining equation (3) and (4), equation (5) was acquired, which related the parameters governing the flow regime transition and described the hydrodynamic condition at the transition.

Using equation (5), the corresponding transition boundary can be acquired at the given solid flow rate, which is compared with the experimental results in Figure 7. It can be seen from Figure 7 that when only introducing effects of the solid flow rate on the dynamic liquid holdup into the model of the trickle bed, it can roughly describe the experimental trend at a lower solid flow rate $\left(u_{s}[?] 2 \mathrm{~mm} / \mathrm{s}\right)$, but at a larger solid flow rate $\left(u_{s}[?] 3 \mathrm{~mm} / \mathrm{s}\right)$, the predicted value and the experimental value will show a large deviation. This result proves the above explanation that the effect of the particle moving on the flow regime transition is not only caused by the decreasing dynamic liquid holdup but also caused by the increasing voidage and the destruction of liquid pockets. Effects of the last two aspects are particularly important at a larger solid flow rate. 


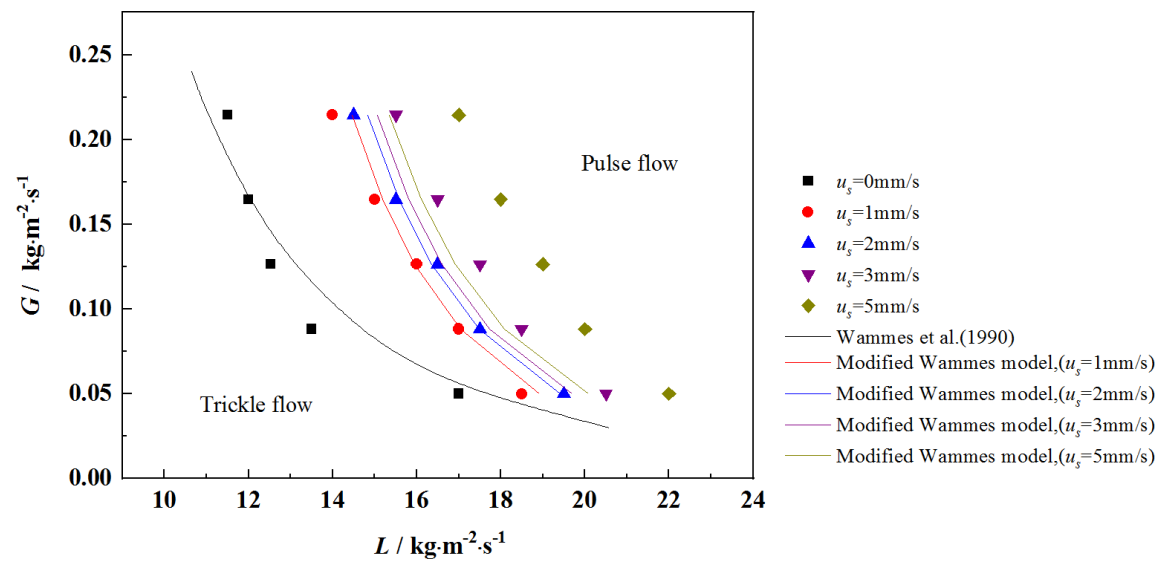

Figure 7. Comparisons of the predictions of modified Wammes model with experimental data in the three-phase moving bed

To get a better understanding of the transition phenomenon, the dynamic liquid holdup at each point of the trickle-to-pulse transition $\left(h_{D}, t r\right)$ for various solid flow rates in the three-phase moving bed was acquired, as shown in Figure 8. It can be seen from Figure 8 that at a constant gas mass flow rate the dynamic liquid holdup required for the transition from trickle flow to pulse flow increases with the increasing solid flow rate. An explanation for this effect is given as follows: (1) an increase in the solid flow rate results in a higher bed porosity and larger interstices between the particles, (2) the larger the solid flow rate, the more liquid pockets or plugs will be destroyed by the movement of particles. Moreover, at relatively higher gas mass flow rate a lower liquid holdup is necessary to initiate the pulses.

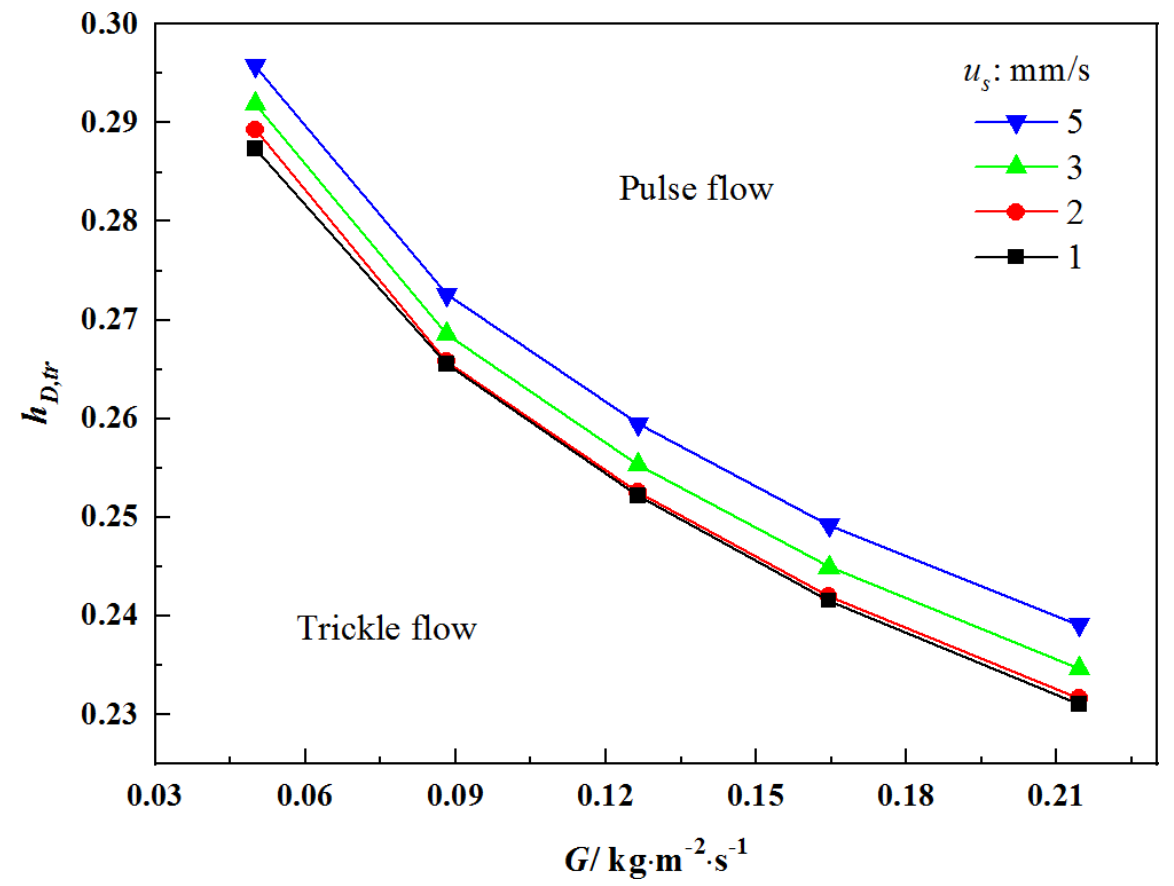

Figure 8. Dynamic liquid holdup at the transition points for various solid flow rates

The critical dynamic liquid holdup at which the local liquid blockages form depends on both the gas mass 
flow rate and solid flow rate, as can be concluded from Figure 8. Referring to the method of Wammes, these hydrodynamic parameters governing the transition between the trickle flow and the pulse flow are related into the equation (6) which describes the conditions at the transition.

Three parameters were estimated by the multiple regression techniques and the final form of the correlation was:

The fitting results are compared with experimental data in Figure 9. The empirical correlation gives an average relative error of $1.67 \%$. The correlations show that, for the given material properties and solid flow rate, the dynamic liquid holdup at the transition between the trickle flow and the pulse flow decreases as the gas mass flow rate increases. At a constant gas mass flow rate there is a shift towards higher dynamic liquid holdup with an increase in the solid flow rate. The present model is valid for the prediction of the trickle-pulse transition boundary in the three-phase moving bed.

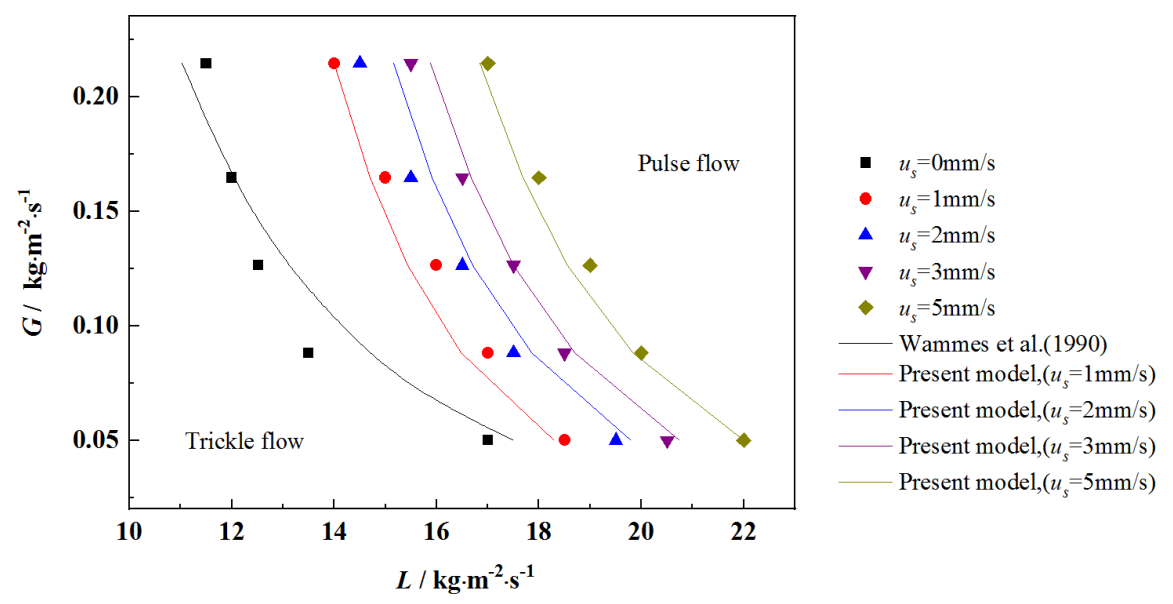

Figure 9. Comparisons of the predictions of the present model with experimental data Effects of the particle moving on the radial liquid distribution

The liquid maldistribution directly affects the reactor performance due to it stands for the improper contacting of gas-liquid phases over catalyst surface and channelling of the flow. It is vitally important to investigate the liquid distribution in the novel three-phase moving bed. Since the movement of particles will destroy the liquid pockets between the particles, it will inevitably affect the radial liquid distribution. The liquid distribution within the bed is rather difficult to quantify, so it is usually expressed by the exit liquid distribution. The exit liquid distribution is measured by a concentric cylinder collector at the outlet, which has been proved as a suitable method in publications ${ }^{47}$. To investigate the effects of the particle moving on the radial liquid distribution, the exit liquid distribution was measured at a given gas and liquid mass flow rates, while the solid flow rate was adjusted to various values.

For the graphical display, the exit liquid distribution was expressed as the mass flow rate measured in each section. Illustrative results are shown in Figures 10, where the liquid mass flow rate in each section is plotted versus the solid flow rate. The dotted lines, representing the uniform flow, are equal to the mean mass flow rate through all zones of the bed. In the trickle bed operation $\left(u_{s}=0 \mathrm{~mm} / \mathrm{s}\right)$, the liquid preferentially flows near the wall, as the bed porosity is higher near the reactor wall ${ }^{48}$. As a result, the mean liquid mass flow rate in the outermost annulus (section 4) was higher than that of the entire cross-section. The liquid mass flow rate of the remaining three annular sections gradually increased from the inside to the outside, but it was always smaller than the average mass flow rate of the entire cross-section. This was mainly due to the uneven arrangement of particles. In the moving bed operation, the radial liquid distribution would be more even to some extent due to the movement of the particles. Taking Figure 10(a) as an example, the liquid 
mass flow rate in section 1 increased with the solid flow rate, indicating that the movement of the particles carrying more liquid into section 1 . As the solid flow rate increased, the liquid mass flow rate in section 2 increased firstly and then decreased. When the solid flow rate was lower than $1 \mathrm{~mm} / \mathrm{s}$, the movement of the particle carried more liquid into section 2 with the increase of solid flow rate. But further increasing the solid flow rate, the movement of the particles carried liquid from section 2 into section 1 . Thereby the liquid mass flow rate in section 2 was reduced. The liquid mass flow rate in section 3 and section 4 decreased with the increasing solid flow rate, indicating that the percentage of wall flow reduced with the increasing solid flow rate. When the feed rate was less than $1.5 \mathrm{~mm} / \mathrm{s}$, the liquid distribution in the three-phase moving bed became more uniform than that in the trickle bed. This was because the movement of particles promoted the radial dispersion of the liquid and improved the liquid distribution. However, when the solid flow rate exceeded $1.5 \mathrm{~mm} / \mathrm{s}$, the liquid mass flow rate in section 1 would far exceed the average liquid mass flow rate of the entire cross-section with the increase of the solid flow rate. This was mainly because the solid flow rate was so large that a large amount of liquid was carried by the moving particles and flowed into the center of the bed. As a result, the liquid distribution became uneven.
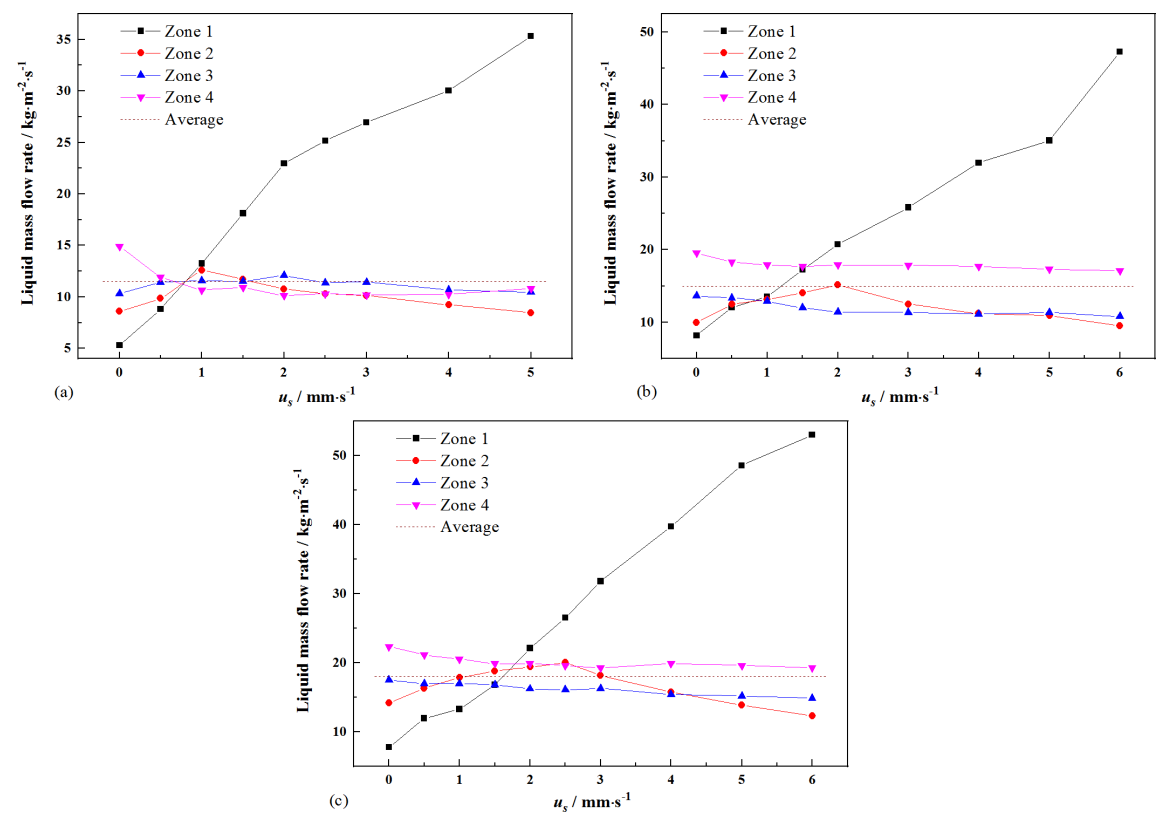

Figure 10. The exit liquid distribution at different solid flow rates

$$
\left(G=0.126 \mathrm{~kg} \cdot \mathrm{m}^{-2} \cdot \mathrm{s}^{-1}\right) \text { (a) } L=12 \mathrm{~kg} \cdot \mathrm{m}^{-2} \cdot \mathrm{s}^{-1} \text {, (b) } L=15 \mathrm{~kg} \cdot \mathrm{m}^{-2} \cdot \mathrm{s}^{-1} \text {, (c) } L=18 \mathrm{~kg} \cdot \mathrm{m}^{-2} \cdot \mathrm{s}^{-1}
$$

The liquid distribution profile was also provided by means of maldistribution factor. For the given gas and liquid mass flow rates, the maldistribution factor at different solid flow rates was shown in Figures 11. As the solid flow rate increased, the maldistribution factor decreased firstly and then increased, which was in agreement with the results in Figure 10. It could also be seen in Figure 11 that the liquid maldistribution occurred at a higher solid flow rate as the liquid mass flow rate increased. In other words, the range of the solid flow rate in which the liquid distribution was more uniform than that in the trickle bed increased with the increasing liquid mass flow rate. 


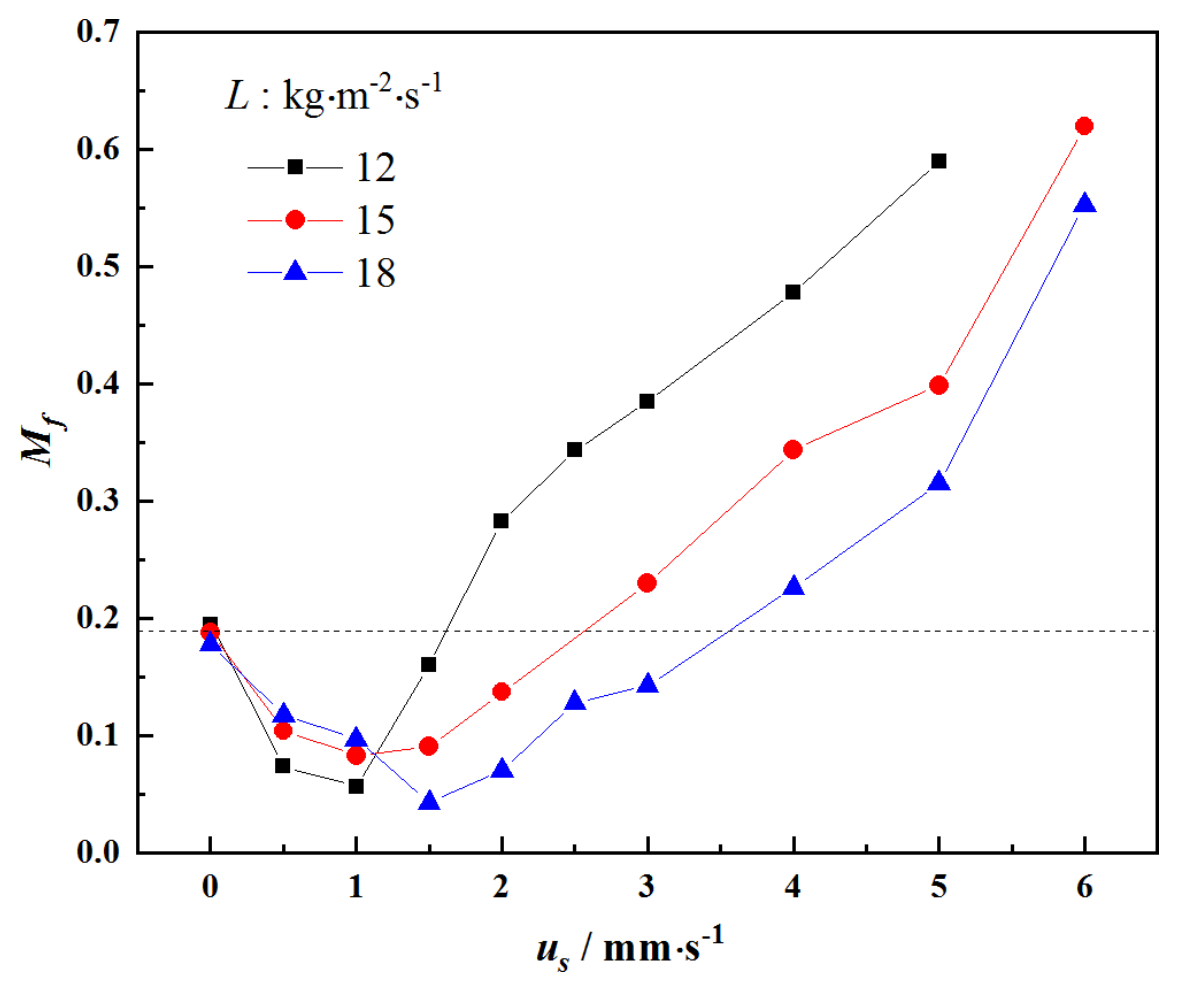

Figure 11. The maldistribution factor at different solid flow rates $\left(G=0.126 \mathrm{~kg} \cdot \mathrm{m}^{-2} \cdot \mathrm{s}^{-1}\right)$

In trickle bed reactors, the gravity-driven nature of liquid flow offers relatively few degrees of freedom to manipulate the liquid distribution. However, in the novel three-phase moving bed, the movement of the particles can improve the radial dispersion of the liquid and increase the freedom of manipulating the performance of the reactor.

\section{Conclusion}

A novel reactor configuration with cocurrent downflow of gas, liquid, and solid phases, named as the threephase moving bed, is proposed for slow three-phase reactions with a large catalyst loading and a rapid deactivation rate of catalyst. A cold-flow experimental apparatus of three-phase moving bed is established to study the transition between the trickle flow regime and the pulse flow regime by the standard deviation of pressure drop and visual observations.

The flow regime map describing the transition between the trickle flow and the pulse flow in the three-phase moving bed is constructed. It is found that the flow regime boundary from the trickle flow to the pulse flow shifts towards higher liquid mass flow rate as the solid flow rate increases. Based on visual observations, pressure drop and dynamic liquid holdup analyses, a conclusion can be drawn that the particle movement affects the formation of local liquid blockages. This effect is explained as follows: (1) an increase in the solid flow rate results in a higher bed porosity and larger interstices between the particles, (2) the dynamic liquid holdup and the mean liquid film thickness decrease with the solid flow rate, (3) the movement of particles will destroy the liquid pockets or plugs between particles. As a result, the liquid films can not collapse in the interstices between the particles to form liquid blockages and initiate the pulses. Therefore, a higher liquid mass flow rate is necessary for the formation of the pulse with the increasing solid flow rate. An empirical correlation is derived from the experimental data for the prediction of the transition between the trickle flow and the pulse flow. The average absolute relative error of this correlation is $1.67 \%$. 
The effects of the particle moving on the radial liquid distribution are investigated with a liquid collector placed at the outlet of the bed. The results show that at a given gas and liquid mass flow rates, the movement of the particles will promote the radial diffusion of the liquid and improve the liquid distribution when the solid flow rate is less than a critical value. But further increasing the solid flow rate, the liquid distribution will become worse than that in the trickle bed. The critical solid flow rate increases with the increasing liquid mass flow rate. In total, compared to the trickle bed, the movement of the particles can increase the freedom of manipulating the performance of the reactor.

\section{Acknowledgments}

The authors acknowledge the support and encouragement of the ExxonMobil Research and Engineering Company, the National Natural Science Foundation of China (21808197), the National Science Fund for Distinguished Young (21525627) and the Science Fund for Creative Research Groups of National Natural Science Foundation of China (61621002).

\section{Notation}

$=$ number of collectors

$=$ maldistribution factor

$=$ diameter of particles, $\mathrm{m}$

$=$ Reynolds number

$=$ dynamic liquid holdup, $\mathrm{m}^{3} / \mathrm{m}^{3}$ reactor volume

$=$ dynamic liquid holdup at the transition point, $\mathrm{m}^{3} / \mathrm{m}^{3}$ reactor volume

$=$ gas mass flow rate, $\mathrm{kg} \cdot \mathrm{m}^{-2} \cdot \mathrm{s}^{-1}$

$=$ liquid mass flow rate, $\mathrm{kg} \cdot \mathrm{m}^{-2} \cdot \mathrm{s}^{-1}$

$=$ solid flow rate, $\mathrm{mm} / \mathrm{s}$

$=$ superficial gas velocity, $\mathrm{m} / \mathrm{s}$

$=$ coefficient defined in eqn $(2)$

$=$ coefficient defined in eqn (6)

$=$ coefficient defined in eqn (6)

$=$ coefficient defined in eqn $(6)$

\section{Greek letters}

$=$ bed porosity

$=$ mean liquid film thickness, $\mathrm{m}$

$=$ total liquid holdup at the transition point, $\mathrm{m}^{3} / \mathrm{m}^{3}$ reactor volume

$=$ density, $\mathrm{kg} / \mathrm{m}^{3}$ 


\section{Subscripts}

$g=$ referring to gas phase

$l=$ referring to liquid phase

$s=$ referring to solid phase

$\operatorname{tr}=$ referring to the transition between trickle and pulse flow

\section{References}

1. Ranade VV, Chaudhari R, Gunjal PR. Trickle bed reactors: Reactor engineering \& applications. Amsterdam: Elsevier, 2011.

2. Satterfield CN. Trickle-bed reactors. AIChE J.,1975;21(2):209-228.

3. Ng K, Chu C. Trickle-bed reactors. Chem. Eng. Prog.,1987;83(11).

4. Iliuta I, Ortiz-Arroyo A, Larachi F, Grandjean BP, Wild G. Hydrodynamics and mass transfer in tricklebed reactors: an overview. Chem. Eng. Sci., 1999;54(21):5329-5337.

5. Gunjal PR, Kashid MN, Ranade VV, Chaudhari RV. Hydrodynamics of trickle-bed reactors: experiments and CFD modeling. Ind. Eng. Chem. Res., 2005;44(16):6278-6294.

6. Iliuta I, Larachi F, Al-Dahhan M. Double-slit model for partially wetted trickle flow hydrodynamics. AIChE J.,2000;46(3):597-609.

7. Al-Dahhan MH, Larachi F, Dudukovic MP, Laurent A. High-pressure trickle-bed reactors: a review. Ind. Eng. Chem. Res., 1997;36(8):3292-3314.

8. Dudukovic MP, Kuzeljevic ŽV, Combest DP. Three-phase trickle-bed reactors. Ullmann's Encyclopedia of Industrial Chemistry, 2014;1-40.

9. Crynes LL, Cerro RL, Abraham MA. Monolith froth reactor: Development of a novel three-phase catalytic system. AIChE J.,1995;41(2):337-345.

10. Roy S, Bauer T, Al-Dahhan M, Lehner P, Turek T. Monoliths as multiphase reactors: a review. AIChE J.,2004;50(11):2918-2938.

11. Jensen KF. Microreaction engineering-is small better?Chem. Eng. Sci., 2001;56(2):293-303.

12. Larachi F, Iliuta I, Belkacemi K. Catalytic wet air oxidation with a deactivating catalyst analysis of fixed and sparged three-phase reactors. Catalysis today, 2001;64(3-4):309-320.

13. Iliuta I, Larachi F. Catalytic wet oxidation in three-phase moving-bed reactors: Modeling framework and simulations for on-stream replacement of a deactivating catalyst. Ind. Eng. Chem. Res.,2012;52(1):370-383.

14. Sie S. Consequences of catalyst deactivation for process design and operation. Appl. Catal. A: General,2001;212(1-2):129-151.

15. Li S, Wang C, Yang Y, et al. Investigation of pressure drop in a cocurrent downflow three-phase moving bed. AIChE J.,2020:e16227.

16. Wang $\mathrm{C}$, Yang $\mathrm{Y}$, et al. Flow regimes in a gas-liquid-solid three-phase moving bed. AIChE J., submitted and under review.

17. Weekman VW, Myers JE. Fluid-flow characteristics of concurrent gas-liquid flow in packed beds. AIChE J.,1964;10(6):951-957.

18. Talmor E. Two-phase downflow through catalyst beds: Part I. Flow maps. AIChE J., 1977;23(6):868874. 
19. Chaudhari R, Ramachandran P. Three-phase catalytic reactors. AIChE J., 1983;26:177-201.

20. Gianetto A, Baldi G, Specchia V, Sicardi S. Hydrodynamics and solid-liquid contacting effectiveness in trickle-bed reactors. AIChE J., 1978;24(6):1087-1104.

21. Christensen G, McGovern S, Sundaresan S. Cocurrent downflow of air and water in a two-dimensional packed column. AIChE J.,1986;32(10):1677-1689.

22. Morsi B, Midoux N, Charpentier J. Flow patterns and some holdup experimental data in trickle-bed reactors for foaming, nonfoaming, and viscous organic liquids. AIChE J., 1978;24(2):357-360.

23. Ling D, Liu P, Cheng ZM. Methanol synthesis in a three-phase catalytic bed under nonwetted condition. AIChE J.,2017;63(1):226-237.

24. Al-Dahhan MH, Dudukovic MP. Pressure drop and liquid holdup in high pressure trickle-bed reactors. Chem. Eng. Sci.,1994;49(24):5681-5698.

25. Larachi F, Iliuta I, Chen M, Grandjean B. Onset of pulsing in trickle beds: evaluation of current tools and state-of-the-art correlation. Can. J. Chem. Eng., 1999;77(4):751-758.

26. Saroha AK, Nigam K. Trickle bed reactors. Reviews in Chem. Eng., 1996;12(3-4):207-347.

27. Horowitz G, Cukierman A, Cassanello M. Flow regime transition in trickle beds packed with particles of different wetting characteristics-check-up on new tools. Chem. Eng. Sci.,1997;52(21-22):3747-3755.

28. Gunjal PR, Ranade VV, Chaudhari RV. Computational study of a single-phase flow in packed beds of spheres. AIChE J.,2005;51(2):365-378.

29. Latifi M, Rode S, Midoux N, Storck A. The use of microelectrodes for the determination of flow regimes in a trickle-bed reactor. Chem. Eng. Sci., 1992;47(8):1955-1961.

30. Schubert M, Kost S, Lange R, Salmi T, Haase S, Hampel U. Maldistribution susceptibility of monolith reactors: Case study of glucose hydrogenation performance. AIChE J.,2016;62(12):4346-4364.

31. Sederman A, Gladden L. Magnetic resonance imaging as a quantitative probe of gas-liquid distribution and wetting efficiency in trickle-bed reactors. Chem. Eng. Sci., 2001;56(8):2615-2628.

32. Anadon LD, Sederman AJ, Gladden LF. Mechanism of the trickle-to-pulse flow transition in fixed-bed reactors. AIChE J.,2006;52(4):1522-1532.

33. Zhao T, Eda T, Achyut S, Haruta J, Nishio M, Takei M. Investigation of pulsing flow regime transition and pulse characteristics in trickle-bed reactor by electrical resistance tomography. Chem. Eng. Sci., 2015;130:8-17.

34. Levec J, Grosser K, Carbonell R. The hysteretic behavior of pressure drop and liquid holdup in trickle beds. AIChE J.,1988;34(6):1027-1030.

35. Sai P, Varma Y. Pressure drop in gas-liquid downflow through packed beds. AIChE J., 1987;33(12):20272036 .

36. Singh BK, Jain E, Buwa VV. Feasibility of Electrical Resistance Tomography for measurements of liquid holdup distribution in a trickle bed reactor. Chem. Eng. J., 2019;358:564-579.

37. Chou T, Worley F, Luss D. Transition to pulsed flow in mixed-phase cocurrent downflow through a fixed bed. Ind. Eng. Chem. Process Design and Development, 1977;16(3):424-427.

38. Saroha AK, Nandi I. Pressure drop hysteresis in trickle bed reactors. Chem. Eng. Sci., 2008;63(12):31143119.

39. Sie S, Krishna R. Process development and scale up: III. Scale-up and scale-down of trickle bed processes. Reviews in Chem. Eng., 1998;14(3):203-252. 
40. Wammes W, Mechielsen S, Westerterp K. The transition between trickle flow and pulse flow in a cocurrent gas-liquid trickle-bed reactor at elevated pressures. Chem. Eng. Sci.,1990;45(10):3149-3158.

41. Iliuta I, Thyrion F. Flow regimes, liquid holdups and two-phase pressure drop for two-phase cocurrent downflow and upflow through packed beds: air/Newtonian and non-Newtonian liquid systems. Chem. Eng. Sci., 1997; 52(21-22):4045-4053.

42. Larachi F, Laurent A, Midoux N. Experimental study of a trickle-bed reactor operating at high pressure two-phase pressure drop and liquid satuation. Chem. Eng. Sci., 1991;46(5-6):1233-1246.

43. Wammes W, Mechielsen S, Westerterp K. The influence of pressure on the liquid hold-up in a cocurrent gas-liquid trickle-bed reactor operating at low gas velocities. Chem. Eng. Sci.,1991;46(2):409-417.

44. Attou A, Ferschneider G. A two-fluid hydrodynamic model for the transition between trickle and pulse flow in a cocurrent gas-liquid packed-bed reactor. Chem. Eng. Sci., 2000;55(3):491-511.

45. Ng K. A model for flow regime transitions in cocurrent down-flow trickle-bed reactors. AIChE J., 1986;32(1):115-122.

46. Grosser K, Carbonell R, Sundaresan S. Onset of pulsing in two-phase cocurrent downflow through a packed bed. AIChE J.,1988;34(11):1850-1860.

47. Herskowitz M, Smith J. Liquid distribution in trickle-bed reactors: Part I. Flow measurements. AIChE J.,1978;24(3):439-450.

48. Saroha AK, Nigam K, Saxena AK, Kapoor V. Liquid distribution in trickle-bed reactors. AIChE J.,1998;44(9):2044-2052. 